\title{
Safety of an Ultrarush (4 Hours) Subcutaneous Immunotherapy Schedule With Cat and Dog Extracts Using an Infusion Pump
}

Uriarte S, Sastre J

Department of Allergy, Fundación Jimenez Diaz, Madrid. Department of Medicine, Universidad Autónoma de Madrid, CIBERES, Instituto Carlos III, Madrid, Spain

J Investig Allergol Clin Immunol 2018; Vol. 28(6): 430-432 doi: 10.18176/jiaci.0307

Key words: Ultra rush immunotherapy. Pet allergy.

Palabras clave: Inmunoterapia Ultra rápida. Alergia a mascotas.

Our group has published 2 case series describing a rush subcutaneous immunotherapy (SCIT) schedule administered using a subcutaneous infusion pump [1,2], in which the maintenance dose was reached after 3 visits. This type of rush protocol with SCIT provides a rapid clinical response, improved adherence, and increased cost-effectiveness owing to the lower number of visits and doses [3-5].

The aim of this prospective, observational study was to shorten the protocol to a 1-day schedule (4 hours) while maintaining its real-world applicability and evaluate its safety, with and without premedication.

We selected patients with rhinitis and/or asthma due to sensitization to cat and dog dander for which treatment with immunotherapy was indicated [6]. For a patient to be included, clinical symptoms had to be clearly related to exposure to cat or dog dander, and specific IgE to cat or dog extract had to be confirmed by skin prick test (ALK) and/or in serum (CAP Thermo Fisher). Randomization was achieved by recruiting consecutive patients, beginning with those who did not receive premedication followed by those who did, at an approximate ratio of $3: 1$

Patients or their guardians signed an informed consent document. The study was approved by the local ethics committee (FJD-ALG-15/01).

Rhinitis and asthma were classified according to the ARIA and the GINA guidelines, respectively.

Premedication consisted of oral administration of $10 \mathrm{mg}$ of cetirizine 2 hours before the patient re-ceived SCIT. Maintenance vials of Alutard SQ cat and dog extracts (ALK) were used as appropriate.

A portable subcutaneous infusion pump (Medis Infusa T) and infusion set (Accu-Chek TenderLink, Roche) were used to administer extracts. The pump was adjusted to deliver $1.2 \mathrm{~mL}$ over 4 hours, and all patients remained under observation for 2 hours after the infusion. One month later, $1 \mathrm{~mL}$ of the extract was administered with the infusion pump over 30 minutes, and 1 month later, patients received $1 \mathrm{~mL}$ of the extract subcutaneously using a 1-mL syringe. Adverse reactions (ARs: local, systemic, immediate, or delayed) were recorded according to the EAACI guidelines [7]. Delayed ARs were monitored by telephone 
Table. Description of Adverse Reactions Using an Infusion Pump for 4 Hours (First Administration)

\begin{tabular}{|c|c|c|c|c|c|c|c|c|c|c|c|c|}
\hline & \multicolumn{2}{|c|}{$\begin{array}{c}\text { Cat } \\
\mathrm{n}=47\end{array}$} & \multicolumn{2}{|c|}{$\begin{array}{c}\text { Dog } \\
n=27\end{array}$} & \multicolumn{2}{|c|}{$\begin{array}{l}\text { Total } \\
\mathrm{N}=74\end{array}$} & \multicolumn{2}{|c|}{$\begin{array}{c}\text { Cat } \\
n=20\end{array}$} & \multicolumn{2}{|c|}{$\begin{array}{c}\text { Dog } \\
n=12\end{array}$} & \multicolumn{2}{|c|}{$\begin{array}{l}\text { Total } \\
\mathrm{N}=32\end{array}$} \\
\hline & No. & $\%$ & No. & $\%$ & No. & $\%$ & No. & $\%$ & No. & $\%$ & No. & $\%$ \\
\hline Adverse reactions & 13 & 27.6 & 3 & 11.1 & 16 & 21.6 & 2 & 10 & 0 & 0 & 2 & $6.3^{\mathrm{a}}$ \\
\hline Systemic reactions & 10 & 21.3 & 3 & 11.1 & 13 & 17.5 & 2 & 10 & 0 & 0 & 2 & $6.3^{b}$ \\
\hline \multicolumn{13}{|l|}{ Time of onset } \\
\hline Immediate & 6 & 60 & 0 & 0 & 6 & 46.2 & 1 & 50 & 0 & 0 & 1 & 50 \\
\hline Late & 4 & 40 & 3 & 100 & 7 & 53.8 & 1 & 50 & 0 & 0 & 1 & 50 \\
\hline \multicolumn{13}{|l|}{ Grade } \\
\hline 1 & 9 & 90 & 3 & 100 & 12 & 92.3 & 1 & 50 & 0 & 0 & 1 & 50 \\
\hline 2 & 1 & 10 & 0 & 0 & 1 & 7.7 & 1 & 50 & 0 & 0 & 1 & 50 \\
\hline 3 & 0 & 0 & 0 & 0 & 0 & 0 & 0 & 0 & 0 & 0 & 0 & 0 \\
\hline 4 & 0 & 0 & 0 & 0 & 0 & 0 & 0 & 0 & 0 & 0 & 0 & 0 \\
\hline \multicolumn{13}{|l|}{ Symptoms } \\
\hline Rhinitis & 5 & 50 & 1 & 33.3 & 6 & 46.2 & 1 & 50 & 0 & 0 & 1 & 50 \\
\hline Conjunctivitis & 1 & 10 & 0 & 0 & 1 & 7.7 & 1 & 50 & 0 & 0 & 1 & 50 \\
\hline Asthma & 1 & 10 & 1 & 33.3 & 2 & 15.4 & 1 & 50 & 0 & 0 & 1 & 50 \\
\hline Urticaria & 4 & 40 & 1 & 33.3 & 5 & 38.5 & 1 & 50 & 0 & 0 & 1 & 50 \\
\hline Angioedema & 2 & 20 & 1 & 33.3 & 3 & 23.1 & 0 & 0 & 0 & 0 & 0 & 0 \\
\hline Other & 2 & 20 & 0 & 0 & 2 & 15.4 & 0 & 0 & 0 & 0 & 0 & 0 \\
\hline Local reactions & 4 & 8.5 & 0 & 0 & 4 & 5.4 & 0 & 0 & 0 & 0 & 0 & $0^{c}$ \\
\hline \multicolumn{13}{|l|}{ Time of onset } \\
\hline Immediate & 0 & 0 & 0 & 0 & 0 & 0 & 0 & 0 & 0 & 0 & 0 & 0 \\
\hline Late & 4 & 100 & 0 & 0 & 4 & 100 & 0 & 0 & 0 & 0 & 0 & 0 \\
\hline \multicolumn{13}{|l|}{ Severity } \\
\hline Mild & 4 & 100 & 0 & 0 & 4 & 100 & 0 & 0 & 0 & 0 & 0 & 0 \\
\hline Moderate & 0 & 0 & 0 & 0 & 0 & 0 & 0 & 0 & 0 & 0 & 0 & 0 \\
\hline Severe & 0 & 0 & 0 & 0 & 0 & 0 & 0 & 0 & 0 & 0 & 0 & 0 \\
\hline
\end{tabular}

${ }^{\mathrm{a} O R, ~} 4.13$ (95\%CI, 0.89-19.19); $P=.06$.

${ }^{\mathrm{b}} \mathrm{OR}, 3.19$ (95\%CI, 0.67-15.08); $P=.14$.

'OR, 4.75 (95\%CI, 0.24-91.10); $P=.30$.

interview 24 and 48 hours after the infusion; patients received instructions to help them evaluate the reaction.

A total of 106 patients were included. Mean age was 32 years (range, 10-63 years). Mean (range) specific IgE in $\mathrm{kUA} / \mathrm{L}$ was as follows: cat dander, $28.63(0.41->100$, all positive); Fel d 1, 26.03 (0.43->100, 61 positive); Fel d 2, 6.81 (0.39-24.9, 7 positive); Fel d 3, 8.09 (0.52-42.5, 35 positive); dog dander, 15.44 (0.51->100, all positive); Can $\mathrm{f}$ $1,11.58$ (0.85->100, 22 positive); Can f 2, 7.46 (0.41-53, 14 positive); Can f $3,8.99$ (0.43-26.9, 8 positive); and Can f 5 , 9.35 (0.35-63.4, 25 positive, 10 monosensitized). Seventy-four patients were not premedicated (47 allergic to cat, 27 allergic to $\mathrm{dog}$ ), and 32 patients received premedication with cetirizine (20 allergic to cat, 12 allergic to dog). Rhinitis was present in $94.3 \%(n=100)$ of patients (moderate-persistent in $77 \%$ ) and asthma in $75.5 \%(\mathrm{n}=80)$ (moderate-persistent in $83.4 \%$ ). Asthma was controlled in $82.1 \%$ and partially controlled in $17.9 \%$. Ninety percent of patients were exposed to the pet at home.

The Table shows the ARs reported during the administration of the first dose. The frequency of ARs with premedication decreased from $21.6 \%$ to $6.3 \%$ (OR, 4.13 ; 95\% CI, 0.89-19.19;
$P=.06$ ), systemic reactions (SRs) decreased from $17.5 \%$ to $6.3 \%(\mathrm{OR}, 3.19 ; 95 \% \mathrm{CI}, 0.67-15.08 ; P=.14)$, and local reactions (LRs) decreased from $5.4 \%$ to $0 \%(\mathrm{OR}, 4.75 ; 95 \% \mathrm{CI}$, 0.24-91.10; $P=.30)$.

During administration of the second dose (74 doses) in the group that did not receive premedication, 3 patients $(4.2 \%)$ had LRs, all of which were delayed, grade 1, and only to cat extract. Of the 2 SRs recorded in this group (2.7\%), 1 was delayed, both were grade 1 , and both to cat extract only. During the third administration (74 doses), 2 had LRs (all delayed, grade 1, and to cat extract), and 11 developed SRs (all immediate, mild, and to cat extract). In the premedicated group, only 1 SR (delayed, grade 2) was seen during the second administration (32 doses) and third administration ( 32 doses), both in the same patient.

No severe SRs were reported. Treatment of ARs consisted of antihistamines $(69 \%)$, intramuscular systemic corticosteroids $(30.8 \%)$, inhaled $\beta_{2}$ agonists (15.4\%), antispasmodics $(7.7 \%)$, and epinephrine (7.7\%). Patients with SRs recovered from symptoms in a mean of 2 hours. None required emergency care. All LRs were induced by cat extract and had a mean duration of 3 days, and only 1 required treatment with oral antihistamine. 
There are few studies against which to compare our 4-hour protocol. Roll et al [3] performed an ultrarush immunotherapy protocol consisting of 6 injections of hymenoptera venom over 4 hours and observed ARs in $17.5 \%$ of cases $(5 \%$ LRs and $12.5 \% \mathrm{SRs}$ ). All SRs were immediate, and most were grade $1(2.5 \%$ grade 2$)$. The results of our study showed a similar frequency of LRs $(5.4 \%)$, although this number was reduced to $0 \%$ with premedication. Of note, the incidence of SRs was higher $(17.6 \%)$, but fell to $6.3 \%$ in the presence of premedication $(P=.06)$, a finding also reported in previous reports using premedication in rush protocols [4]. In another study using venom extract in which the full dose was injected over 3.5 hours [8], $6.5 \%$ of patients experienced SRs. When the present results are compared with our previous experience using an infusion pump [1,2] and a 3-day schedule, a similar frequency of LRs was found without premedication $(6.4 \%$ $8.5 \%$ vs $5.4 \%$, 0 with premedication). A higher number of SRs was found with the present ultrarush protocol (3.9\%-4.9\% vs $17.5 \%, 6.3 \%$ with premedication). When comparing the ARs recorded here against other 2 -day rush protocols, we observed a lower frequency of reactions, even without premedication [9]. The higher incidence of ARs to cat extract is likely due to a higher concentration of major allergen in the extract $(15 \mu \mathrm{g} / \mathrm{mL}$ Fel d 1 vs $3.2 \mu \mathrm{g} / \mathrm{mL}$ Can f 1 , and $0.72 \mu \mathrm{g} / \mathrm{mL}$ Can f 5; as measured by J. Lindhom, Thermo Fisher Scientific, Uppsala, Sweden).

In conclusion, this is the first real-life study to evaluate the safety of a 4-hour ultrarush immunotherapy protocol in patients with rhinitis and/or asthma. While no ARs were severe, a greater number were recorded than in standard protocols, although this number is similar to that of longer rush protocols when patients are premedicated with antihistamine. The use of an infusion pump reduces the number of injections and can be applied when indicated in real life. Larger scale studies will be necessary to confirm our findings.

\section{Acknowledgments}

We are grateful to Oliver Shaw for editorial assistance

Funding

This study was partly funded by ALK Spain.

\section{Conflicts of Interest}

JS has served as a consultant to ThermoFisher, MSD, Novartis, Genetech, Sanofi, Leti, Roche, FAES FARMA, Mundipharma, and GSK and has received lecture fees from Novartis, GSK, Stallergenes, LETI, and FAES FARMA. He has also received grant support for research from ThermoFisher. SU declares that she has no conflicts of interest.

\section{References}

1. Sastre J, Vallejo L, Hernández E, Fernández-Nieto $M$, Nieto PR. Rush allergen subcutaneous immunotherapy administered with infusion pump. Ann Allergy Asthma Immunol. 2011;107(5):459-60.
2. Uriarte Obando SA, Sastre Domínguez J. Safety of rush subcutaneous immunotherapy adminis-tered in real life using an infusion pump. Ann Allergy Asthma Immunol. 2015; 115(6):527-9.

3. Roll A, Hofbauer G, Ballmer-Weber BK, Schmid-Grendelmeier P. Safety of specific immuno-therapy using a four-hour ultrarush induction scheme in bee and wasp allergy. J Investig Allergol Clin Immunol. 2006;16(2):79-85.

4. Cox L. Advantages and disadvantages accelerated immunotherapy schedules. J Allergy Clin Immunol. 2008;122(2):432-4.

5. Calabria CW. Accelerated immunotherapy schedules. Curr Allergy Asthma Rep. 2013;13(4):389-98.

6. Alvarez-Cuesta E, Bousquet J, Canonica GW, Durham SR, Malling HJ, Valovirta E; EAACl, Immunotherapy Task Force. Standards for practical allergen-specific immunotherapy. Allergy. 2006;61 Suppl 82:1-20.

7. Zuberbier T, Bachert C, Bousquet PJ, Passalacqua G, Canonica WG, Merk $H$, et al. GA²LEN/EAACI pocket guide for allergenspecific immunotherapy for allergic rhinitis and asthma. Allergy. 2010;65:1525-30

8. Nittner-Marszalska M, Cichocka-Jarosz E, Małaczyńska T, Kraluk B, Rosiek-Biegus M, Kosinska M, et al. Safety of Ultrarush Venom Immunotherapy: Comparison Between Chil-dren and Adults. J Investig Allergol Clin Immunol. 2016;26(1):40-7.

9. Justicia JL, Barasona MJ, Serrano P, Moreno C, Guerra F. Predicting patients at high-risk of systemic reactions to cluster allergen immunotherapy: a pilot prospective observational study. J Investig Allergol Clin Immunol. 2007;17:386-92.

Manuscript received July 7, 2018; accepted for publication August 20, 2018

Joaquín Sastre

Department of Allergology Hospital Fundación Jimenez Diaz Madrid, Spain E-mail: jsastre@fjd.es 